\title{
The Magnetic Properties and Microwave Absorbing Characteristics of Ni-Zn Ferrite
}

\author{
H.J.KWON, D.H.HAN, J.T.YOO, T.H.KANG and W.D.HUR
}

R \& D Lab., Samwha Electronics Co., LTD., 211-1, Jangji-ri, Dongtan-myoun, Hwasung-gun, Kyoung ki-do, Korea.

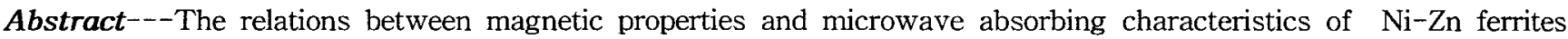
were examined. As the initial permeability of $\mathrm{Ni}-\mathrm{Zn}$ ferrite material increased, the microwave absorbing performance of ferrite absorber was improved in the $\mathrm{MHz}$ region. From the results of these experiments, we could develop the ferrite absorber having superior microwave absorbing performance in the $10 \mathrm{MHz}-400 \mathrm{MHz}$ region.
\end{abstract}

\section{I . INTRODUCTION}

Microwave absorbing characteristics such as the matching frequency, matching thickness, and band-width are influenced by the magnetic properties and resonance phenomena of ferrite material [1]. Thus, in order to develop high performance ferrite absorber, it is important to investigate the relationship between the magnetic properties and microwave absorbing characteristics of ferrite absorber. But little work has been done on this relationship of ferrite material.

The purpose of this study was to investigate the effect of the magnetic properties such as initial permeability $\left(\mu_{\mathrm{i}}\right)$, saturation magnetization $\left(\sigma_{\mathrm{s}}\right)$ and coercive force $\left(\mathrm{H}_{\mathrm{c}}\right)$ on the microwave absorbing characteristics of $\mathrm{Ni}-\mathrm{Zn}$ ferrites.

\section{II .EXPERIMENTAL}

$\mathrm{Ni}-\mathrm{Zn}$ ferrites were prepared by conventional ceramic process. Raw materials ( $\mathrm{NiO}, \mathrm{ZnO}$ and $\alpha$ $-\mathrm{Fe}_{2} \mathrm{O}_{3}$ ) were mixed, calcined, milled, axially pressed and then sintered at $1150^{\circ} \mathrm{C}$ for 2 hours in the air. The initial permeability and other magnetic properties of toroidally shaped specimens were measured by an impedance analyzer (Hewlett-Packard, HP-4194) and a B-H analyzer(Iwatsu, SY-8232), respectively. The scattering parameters $\left(\mathrm{S}_{11}, \mathrm{~S}_{21}\right)$ of toroidally shaped ferrite(outer dia. $=7.0 \mathrm{~mm}$, inner dia. $=3.0 \mathrm{~mm}$ ) were measured by a Network analyzer (Hewlett -Packard , HP-8753) in the frequency range 300 $\mathrm{kHz} \sim 1 \mathrm{GHz}$. The complex permeability and permittivity were determined from the scattering parameters [2] .

Also, the saturation magnetization $\left(\sigma_{\mathrm{s}}\right)$ of $\mathrm{Ni}-\mathrm{Zn}$ ferrites was measured by VSM(LDJ 9101).

\section{RESULTS AND DISCUSSION}

\section{III-1) The Magnetic Properties of Ni-Zn ferrites}

The frequency dependence of the initial permeability $\left(\mu_{\mathrm{i}}\right)$ is shown in Fig.1.

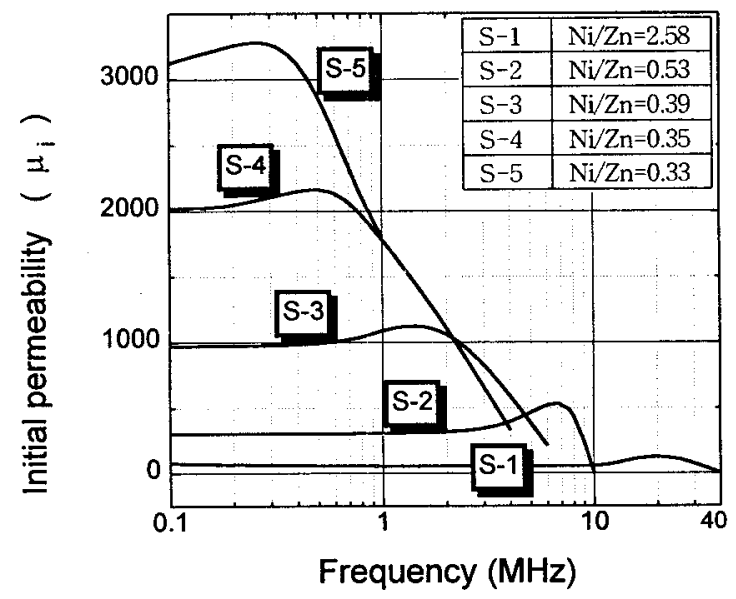

Fig.1 The frequency dependence of $\mu_{\mathrm{i}}$.

As can be seen in Fig.1, $\mu_{\mathrm{i}}$ increases but the frequency dependence of $\mu_{\mathrm{i}}$ becomes worse with decreasing the $\mathrm{Ni} / \mathrm{Zn}$ ratio.

Fig.2 represents the variation of maximum flux density $\left(\mathrm{B}_{\mathrm{m}}\right)$, saturation magnetization $\left(\sigma_{\mathrm{s}}\right)$ and coercive force $\left(\mathrm{H}_{\mathrm{c}}\right)$ with $\mathrm{Ni} / \mathrm{Zn}$ ratio.

As shown in Fig.2, the $\mathrm{B}_{\mathrm{m}}, \mathrm{H}_{\mathrm{c}}$ and $\sigma_{\mathrm{s}}$ increase with increasing $\mathrm{Ni} / \mathrm{Zn}$ ratio. This behavior is probably due to the increased $\mathrm{A}-\mathrm{B}$ exchange interaction with increasing $\mathrm{Ni} / \mathrm{Zn}$ ratio in the case of $\mathrm{Ni}-\mathrm{Zn}$ spinel ferrite [3] .

We manufactured the ferrite absorbers of these $\mathrm{Ni}-\mathrm{Zn}$ ferrites having different magnetic properties and examined the microwave absorbing characteristics of ferrite absorber. 


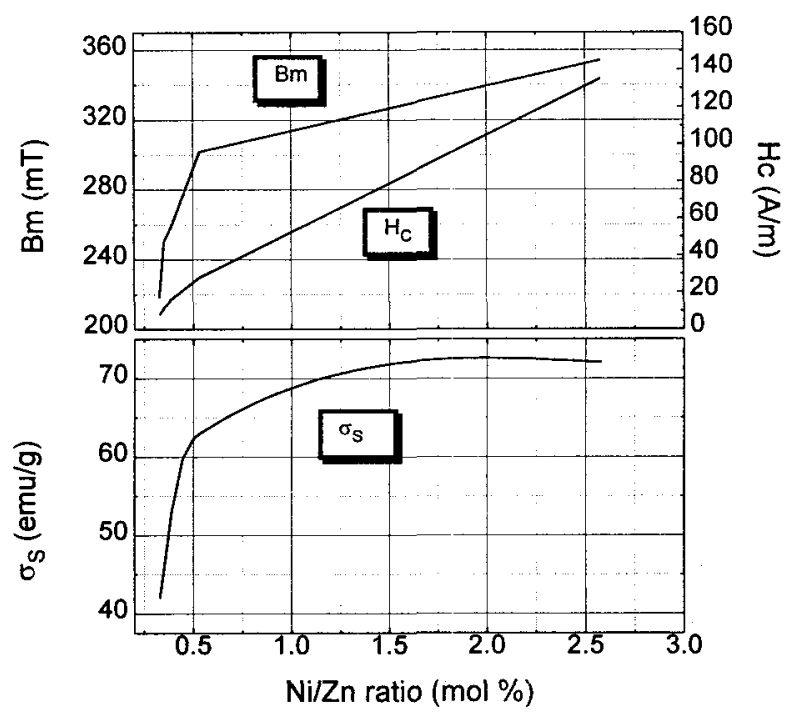

Fig.2 The variation of $\mathrm{B}_{\mathrm{m}}, \sigma_{\mathrm{s}}$ and $\mathrm{H}_{\mathrm{c}}$ with $\mathrm{Ni} / \mathrm{Zn}$ ratio.

Magnetic properties of $\mathrm{Ni}-\mathrm{Zn}$ ferrites developed in this study were represented in Table I .

Table I .The Magnetic Characteristics of $\mathrm{Ni}-\mathrm{Zn}$ Ferrites (freq. : $100 \mathrm{kHz}, \mathrm{Hm}: 800 \mathrm{~A} / \mathrm{m}$ ).

\begin{tabular}{llcrcc}
\hline Material & $\begin{array}{c}\mathrm{Ni} / \mathrm{Zn} \\
\text { ratio }\end{array}$ & $\begin{array}{c}\mu_{\mathrm{i}} \\
(100 \mathrm{kHz})\end{array}$ & $\begin{array}{c}\mathrm{B}_{\mathrm{m}} \\
(\mathrm{m} \mathrm{n})\end{array}$ & $\begin{array}{c}\mathrm{H}_{\mathrm{c}} \\
(\mathrm{A} / \mathrm{m})\end{array}$ & $\begin{array}{c}\sigma_{\mathrm{s}} \\
(\mathrm{emu} / \mathrm{g})\end{array}$ \\
\hline $\mathrm{S}-1$ & 2.58 & 89 & 354 & 135 & 72 \\
$\mathrm{~S}-2$ & 0.53 & 323 & 302 & 28 & 63 \\
$\mathrm{~S}-3$ & 0.39 & 971 & 259 & 16 & 53 \\
$\mathrm{~S}-4$ & 0.35 & 2074 & 250 & 12 & 46 \\
$\mathrm{~S}-5$ & 0.33 & 3122 & 218 & 8 & 42 \\
\hline
\end{tabular}

\section{III-2) The Complex Permeability and Microwave} Absorbing Characteristics.

In order to investigate the relation between magnetic properties and microwave absorbing characteristics, the complex permeability of $\mathrm{Ni}-\mathrm{Zn}$ ferrites was examined in the frequency range of $300 \mathrm{kHz}-1 \mathrm{GHz}$. The frequency dependence of complex permeability of $\mathrm{Ni}-\mathrm{Zn}$ ferrites is shown in Fig.3. As shown in Fig.3, the resonance phenomena are observed. In $\mathrm{Ni}-\mathrm{Zn}$ ferrites, these resonance phenomena occurred in this frequency range are believed to be due to spin rotational resonance [4] .

It is also found that the resonance frequency is shifted toward lower frequency with decreasing $\mathrm{Ni} / \mathrm{Zn}$ ratio.

For spin rotation, general model is the Snoek one [5] which predicts the resonance frequency given by

$$
\mathrm{f}_{\mathrm{r}}=(\gamma / 2 \pi) \mathrm{H}_{\mathrm{a}}
$$

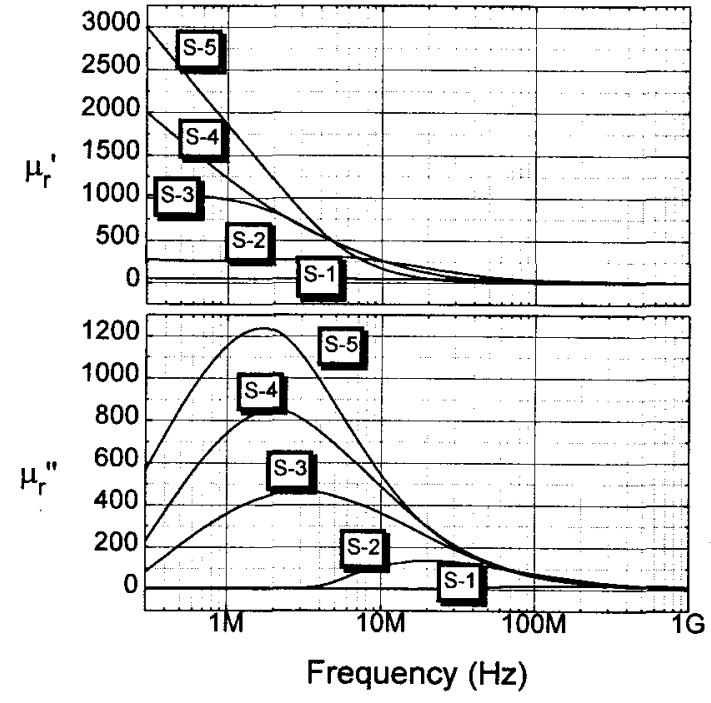

Fig.3 The frequency dependence of complex permeability of $\mathrm{Ni}-\mathrm{Zn}$ ferrites.

where $\gamma$ is gyromagnetic ratio, $\mathrm{H}_{\mathrm{a}}$ is the anisotropy field and $\mathrm{f}_{\mathrm{r}}$ is the spin rotational resonance frequency of material. Equation (1) indicates that the spin rotational resonance frequency depends on the anisotropy field.

From the results of Table I, it could be known that the coercive force $\left(\mathrm{H}_{\mathrm{c}}\right)$ of $\mathrm{S}-1$ material $(\mathrm{Ni} / \mathrm{Zn}=2.58)$ and $\mathrm{S}-5$ material $(\mathrm{Ni} / \mathrm{Zn}=0.33)$ was $135 \mathrm{~A} / \mathrm{m}, 8 \mathrm{~A} / \mathrm{m}$ respectively. Thus, decreasing the spin rotational resonance frequency with decreasing $\mathrm{Ni} / \mathrm{Zn}$ ratio indicates that the anisotropy becomes smaller as the $\mathrm{Ni} / \mathrm{Zn}$ ratio decreases.

Fig.4 shows the structure of flat and grid absorber [6] manufactured in this study.

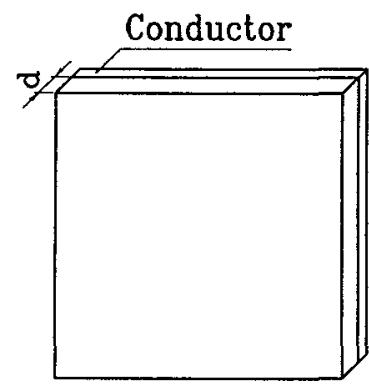

(a)

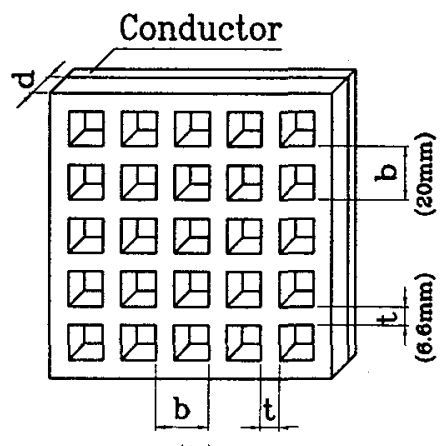

(b)
Fig.4 The structure of flat and grid absorber.
(a) : flat absorber
(b) : grid absorber
( $d$ : Absorber thickness )

For microwave absorbing layer backed by a metal plate, the normalized input impedance $\left(Z_{\text {in }}\right)$ at the absorber surface is given by [7] 


$$
Z_{\text {in }}=1=\sqrt{\mu_{r} / \varepsilon_{r}} \tanh \left[j(2 \pi / c) \sqrt{\mu_{r} \varepsilon_{r}} f d\right]
$$

where $\mu_{\mathrm{r}}$ is the complex permeability $\left(\mu_{\mathrm{r}}^{\prime}-\mathrm{j}\right.$ $\left.\mu_{\mathrm{r}}^{\prime \prime}\right), \varepsilon_{\mathrm{r}}$ is the complex permittivity $\left(\varepsilon_{\mathrm{r}}^{\prime}-\mathrm{j} \varepsilon_{\mathrm{r}}^{\prime \prime}\right)$, $c$ is the velocity of light, $f$ is the frequency, and $\mathrm{d}$ is the thickness of absorber. This equation is called the zero reflection condition for an absorber. And the frequency and thickness that satisfy eq.(2) are called impedance matching frequency and matching thickness of absorber.

The reflection loss $(\mathrm{dB})$ is function of $Z_{\mathrm{in}}$, and the reflection loss of the microwave absorber can be calculated at given $f$ and $d$ using equation (3):

$$
\mathrm{dB}=20 \log \left|\left(Z_{\text {in }}-1\right) /\left(Z_{\text {in }}+1\right)\right|
$$

The reflectivity characteristics of grid structure are calculated for normal incidence of plane wave by using the spatial network method [6]. In this calculation procedure, the electromagnetic field is expressed in the equivalent circuit of the three-dimensional lattice work [8] .

The calculated microwave absorbing results with thickness variation are represented in Fig.5 and Table II.

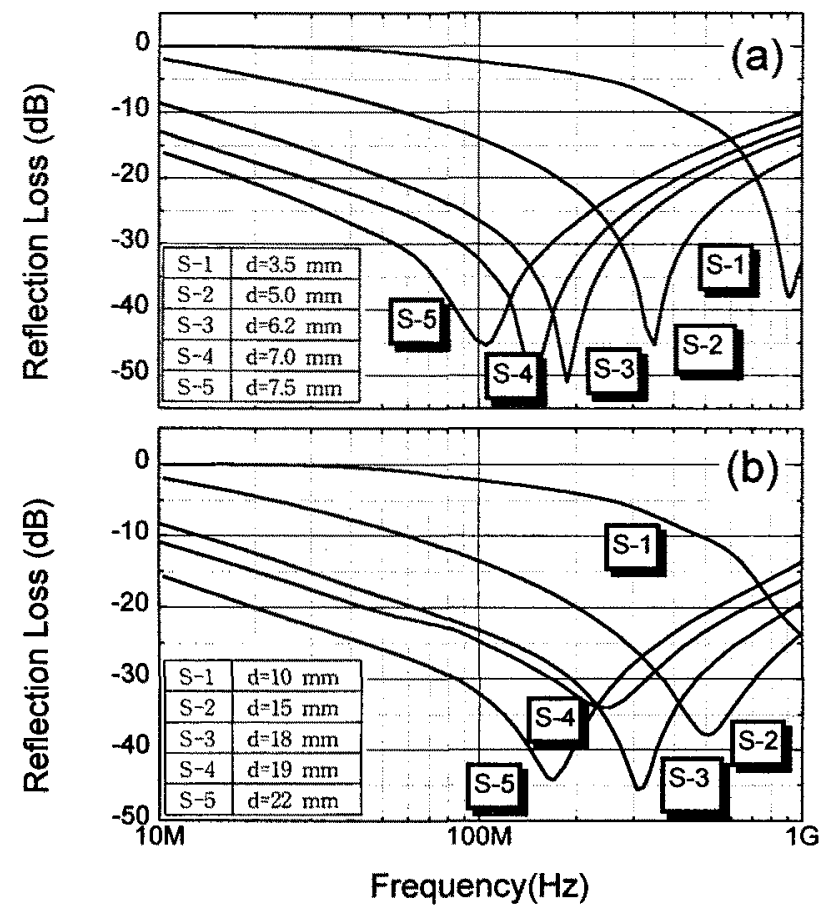

Fig.5 The reflection loss of flat and grid absorber (a): flat absorber (b): grid absorber (d : Absorber thickness)

From the results of Fig.5 and Table II, it can be found that the microwave absorbing frequency range of ferrite absorber is moving to lower frequency band according to increasing initial permeability.

With decreasing $\mathrm{Ni} / \mathrm{Zn}$ ratio, the matching frequency $(\mathrm{fm})$ and band-width $(\geq-20 \mathrm{~dB})$ of flat
Table $\amalg$. The Microwave Absorbing Characteristics of $\mathrm{Ni}-\mathrm{Zn}$ Ferrites.

[Flat Absorber]

\begin{tabular}{cccc}
\hline Material & $\begin{array}{c}\text { Matching } \\
\text { Freq.(MHz) }\end{array}$ & $\begin{array}{c}\text { Matching } \\
\text { Thickness(mm) }\end{array}$ & $\begin{array}{c}\text { Band-width } \\
(\geq-20 \mathrm{~dB})\end{array}$ \\
\hline S-1 & 910 & 3.5 & $750 \sim 1,470 \mathrm{MHz}$ \\
S-2 & 350 & 5.0 & $190 \sim 710 \mathrm{MHz}$ \\
S-3 & 188 & 6.2 & $54 \sim 470 \mathrm{MHz}$ \\
S-4 & 143 & 7.0 & $39 \sim 410 \mathrm{MHz}$ \\
S-5 & 110 & 7.5 & $28 \sim 300 \mathrm{MHz}$ \\
\hline IGrid Absorber I & & \\
\hline Material & Matching & Matching & Band-width \\
\multicolumn{5}{c}{ Freq.(MHz) } & Thickness(mm) & $(\geq-20 \mathrm{~dB})$ \\
\hline S-1 & 980 & 10 & $870 \sim 1,900 \mathrm{MHz}$ \\
S-2 & 500 & 15 & $200 \sim 1,300 \mathrm{MHz}$ \\
S-3 & 310 & 18 & $65 \sim 920 \mathrm{MHz}$ \\
S-4 & 250 & 19 & $45 \sim 700 \mathrm{MHz}$ \\
S-5 & 180 & 22 & $20 \sim 520 \mathrm{MHz}$ \\
\hline \multicolumn{5}{c}{} & \multicolumn{3}{c}{}
\end{tabular}

and grid absorber are shifted toward lower frequency, whereas the matching thickness $(\mathrm{dm})$ increase. Therefore, in order to control the microwave absorbing characteristics, it is important to control the magnetic properties such as $\mu_{\mathrm{i}}, \mathrm{B}_{\mathrm{m}}, \sigma_{\mathrm{s}}, \mathrm{H}_{\mathrm{c}}$ and $\mathrm{f}_{\mathrm{r}}$ of ferrite material.

\section{CONCLUSION}

We focused on the effect of magnetic properties on the microwave absorbing characteristics of ferrite absorber.

The matching frequency $\left(f_{m}\right)$ of ferrite absorber was proportional to its coercive force $\left(\mathrm{H}_{\mathrm{c}}\right)$ and saturation magnetization $\left(\sigma_{s}\right)$ in the $\mathrm{Ni}-\mathrm{Zn}$ ferrite.

It was also seen that the microwave absorbing performance was improved in the $\mathrm{MHz}$ region as the initial permeability increased.

From these experiments, it can be concluded that the microwave absorbing characteristics of ferrite absorber are controlled by adjusting the magnetic properties of ferrite material.

\section{REFERENCES}

1. H.J.Kwon, J.Y.Shin and J.H.Oh J.Appl.Phys 75, No.10, 6109 (1994).

2. W.B. Weir, Proc.IEEE 62, 33 (1974)

3. J.smit and H.P.J.Wijn, Ferrites, pp 147-160 (Wiley, NewYork,1959)

4. G.T.Rado, Rev.Mod.Phys.25, 81 (1953).

5. J.L.Snoek, Physica 14, 207 (1948).

6. Y.Naito, M.Takahashi,H.Anzai,T.Mizumoto and H.sano, Tech.Group.Dig IEICE, JAPAN, EMCJ 91-81 (in Japanese) (1992).

7. H.M.Musal and H.T.Hahn, IEEE Trans.Magn. MAG-25, 3851 (1989)

8. N.Kukutsu, N.Yoshida and I.Fukai, IEEE Trans.on MTT,36, 114, Jan (1988) 